\title{
Thyrotoxic Hepatitis in a Patient with Subacute Thyroid: A Case Report
}

\author{
Özlem BULUZ ${ }^{1}$, Ayça Zeynep KUTLU², Seçil ARICA ${ }^{1}$ \\ ${ }^{1}$ Prof. Dr. Cemil Taşcıoğlu City Hospital, Department of Family Medicine, Istanbul \\ ${ }^{2}$ Istanbul University Istanbul Faculty of Medicine, Istanbul, Turkey
}

\begin{abstract}
Subacute granulomatous thyroiditis (DeQuervain's disease) is a self-limiting inflammatory disease which is often diagnosed in the "temporary thyrotoxicosis period" during the initial phases of the disease. Liver enzyme abnormalities can be seen in the course of thyrotoxicosis. The definition of "thyrotoxic hepatitis" is used to describe the elevation of liver enzymes after excluding other causes. In this case report, a female patient who developed thyrotoxic hepatitis in the course of her subacute thyroiditis, is reported to remind the importance of evaluating liver functions in the follow-up of subacute thyroiditis.
\end{abstract}

Turk J Int Med 2021;3(Supplement 1):S90-S91

DOI: $10.46310 /$ tjim.878062

Keywords: Thyrotoxic Hepatitis, Subacute Thyroiditis, Liver Enzyme Abnormalities

\section{Introduction}

Subacute

(DeQuervain's

granulomatous

thyroiditis disease) is a self-limiting inflammatory disease with a triphasic clinical course -hyperthyroidism, hypothyroidism and euthyroidism- frequently seen in young and middleaged women during seasonal transition periods. In the etiology, viral (adenovirus, coxsackievirus, mumps, EBV, and influenza) infections and genetic predisposition (HLA-BW35) are blamed while autoimmune response is not. Weakness, fatigue, myalgia, mild/moderate fever and arthralgia are common features in patients with subacute thyroiditis. Severe neck pain in the thyroid gland region often radiating to the jaws or ears is observed. On physical examination, the thyroid gland is enlarged and sensitive. In laboratory tests ESR, CRP are elevated. The disease is often diagnosed in the early "temporary thyrotoxicosis period". In this phase, thyroid gland parenchyma destruction secondary to inflammation causes increase in blood fT3 and fT4 levels and suppression of TSH. Thyroid radioactive iodine131 uptake (RAIU) is low ( $<2 \%$ at the 24th hour). After stored colloid in the follicles is completely discharged, hypothyroidism phase initiates. During the recovery period, parenchyma cells regain hormone

\begin{tabular}{l|l}
\hline Addressfor Correspondence: \\
Özlem BULUZ \\
Prof. Dr. Cemil Taşc1oğlu City Hospital, Department of Family Medicine, Istanbul
\end{tabular}


producing capacity in several weeks and the euthyroid period is entered. The hypothyroidism rarely becomes permanent. ${ }^{1,2}$

Liver enzyme abnormalities can be seen in the course of thyrotoxicosis. The diagnosis of "thyrotoxic hepatitis" can be made after excluding other causes of liver pathology. In the pathogenesis of thyrotoxic hepatitis, the inability to compensate for the increase in hepatic oxygen demand (perivenular hypoxemia), autoimmunity, thyrotoxicosis complications such as heart failure. etc are held responsible. Thyrotoxic hepatitis clinical picture ranges from asymptomatic enzyme elevation to severe liver damage but is generally self-limiting. ${ }^{3-5}$ Here, we want to report a patient who had concurrent hepatitis in the thyrotoxic period of subacute thyroiditis and whose clinic improved with symptomatic treatment, to remind the importance of evaluating liver functions in the follow-up of subacute thyroiditis.

\section{Case Report}

A 35-year-old female patient without known chronic disease was admitted to our clinic with complaints of generalized body pain, weakness, hair loss, palpitations, dyspnea on exertion and sore throat for a month. Physical examination showed the thyroid gland was enlarged and tender to palpation. Lab studies showed TSH: $0.01 \mathrm{mU} / \mathrm{L}$ (0.34-5.60), fT4: 41.29 ng/L (6.1-11.2), anti-TPO: $0.3 \mathrm{kU} / \mathrm{L}(0-9)$, ALT: $110 \mathrm{U} / \mathrm{L}(0-50)$, AST: $118 \mathrm{U} / \mathrm{L}$ (<35), ALP: 254U/L(33-98), GGT: 129U/L (0-38), and CRP: $94.35 \mathrm{mg} / \mathrm{L}(<5)$. Hemogram, ferritin, vitamin B12, glucose and creatinine results were normal. Thyroid ultrasonography revealed thyroid parenchyma was hypoechoic-heterogeneous and the gland was diffusely enlarged. The RAIU test was found to be $4 \%(8-15)$ at the 2 nd hour and $1 \%$ (15-35) at the 24th hour. The patient was started on $1 \mathrm{mg}$ single dose dexamethasone, propranolol $40 \mathrm{mg} \mathrm{2 \times 1/2}$, (etodolac $400 \mathrm{mg} 2 \times 1$, paracetamol $500 \mathrm{mg} \mathrm{2x1}$, when necessary). Tests performed 5 weeks post-treatment showed: TSH: $13.2 \mathrm{mU} / \mathrm{L}$ (0.34-5.60), fT4: $4.22 \mathrm{ng} / \mathrm{L}$ (6.1-11.2), ALT: $21 \mathrm{U} / \mathrm{L}$ (0-50), AST: 23 U/L (<35), ALP: 83 U/L (33-98),
GGT: $30 \mathrm{U} / \mathrm{L}$ (0-38), and CRP: $1.12 \mathrm{mg} / \mathrm{L}(<5)$. The patient, who was treated with L-thyroxine during the hypothyroid period, was planned to be followed up with 4 weeks intervals.

\section{Discussion}

Since thyrotoxicosis occurs without hyperthyroidism in the course of subacute thyroiditis, there is no place for antithyroid drugs in the treatment. Beta blocker drugs are used to reduce the systemic effect of elevated thyroid hormones during the thyrotoxicosis phase while analgesics/NSAIDs and short-term steroid therapy can be used for fever and pain. Similar to the conditions in hyperthyroidism, the possibility of developing acute hepatitis during thyrotoxicosis of subacute thyroiditis should be kept in mind. The patient's liver functions should be monitored regularly. Likewise, thyroid functions should definitely be evaluated in the etiology of patients presenting with acute hepatitis.

\section{Conflict of Interests}

Authors declare that there are none.

\section{Acknowledgment}

This study has been presented in $17^{\text {th }}$ Uludag Internal Medicine National Winter Congress, $6^{\text {th }}$ Bursa Family Medicine Association National Congress, $11^{\text {th }}$ Uludag Internal Medicine Nursing Congress, 5-7 March 2021, Bursa, Turkey.

\section{References}

1. Acar GÖ, Toprak M. Thyroid Diseases. Clinical Development. 2012;25:106-14 (in Turkish).

2. Ecemis GC, Çolak R. Tiroiditis. Journal of Experimental and Clinical Medicine. 2013;29(4S):321-7 (in Turkish). doi: 10.5835/jecm.omu.29.s4.020.

3. Kutlu O, Ecirli S, Can M, Keskin M, Sakin A. Tirotoksik hepatitli Graves hastasında metimazole baglı toksik hepatit. Poster presented at: 31. National Gastroenterology Week. November 25-30, 2014, Antalya, Turkey.

4. Av $\square$ ar MG, Kutlu O. Severe acute thyrotoxic hepatitis in the course of subacute thyroiditis: A case report. Poster presented at: 20. National Internal Diseases Congress, October 10-14, 2018, Antalya, Turkey.

5. Kutlu O, Duran C, Kocar K, Sevimli Burnik F, Ecirli S. Treatment of liver enzyme elevation due to thyrotoxicosis with methimazole. Poster presented at: 10 . Uludag Internal Diseases Winter Congress. March 9-12, 2014, Uludag, Turkey. 